\title{
Dimmable High Power LED Driver Using Fuzzy Logic Controller
}

\author{
Rizky Fatur Rochman ${ }^{1}$, Eka Prasetyono ${ }^{2}$, Rachma Prilian Eviningsih ${ }^{3}$
}

\begin{abstract}
The use of lighting loads is one of the crucial matters which increases every year. The increasing use then leads to the development of brighter and longer-lasting sources. In addition, the conventional use of lighting loads today, which only emit light at its maximum intensity, does not allow the consumers to adjust the brightness level as needed. Consequently, this condition may cause energy wastage. The LED lighting system is gaining popularity as it is widely used in a wide range of applications. The advantages of LEDs, such as its compact size and varied lamp colors, replace conventional lighting sources. The linear setting of the driver topology using the flyback converter was aimed to control the LEDs with a constant current in order to adjust the variation of the LED light intensity. The closed-loop driver circuit with flyback converter topology was designed as an LED driver with a given load specification from the LED string. A dimmable feature was included for adjusting the intensity of the light produced by the LEDs. Eventually, the fuzzy logic controller (FLC) method was applied to the integrated change setting to obtain a dynamic response.
\end{abstract}

Keyword-LED, Flyback Converter, Fuzzy Logic Controller (FLC), Driver LED.

\section{INTRODUCTION}

Light emitting diode (LED) is a lighting technology with better color, performance, flexibility, and efficiency than previous lighting technologies [1]. Although many innovations on LEDs have been discovered for the last decade, researchers and producers are striving to improve LEDs for long-term use. The various advantages of LEDs make these lamps are widely used to replace conventional lamps for diverse lighting installation needs. LEDs are growing in popularity as they are used in a wide range of applications. They are claimed to have an efficiency of 120 lumens per watt and a lifespan of over 50,000 hours. One of the widely applied uses of LEDs today is in floodlight, residential lighting, and commercial need, which requires thousands of lumens power [2]. Turning on the LEDs requires a driver circuit to regulate the voltage supplied to the LEDs. A wide variety of power from the power LED adjusted to the needs of the lumens requires a variety of LED drivers. The driver circuit is the core of the LED lamps serving to provide supply to LEDs. The driver circuit also includes a DC$\mathrm{DC}$ rectifier and converter. The bridge rectifier converts the ac supply to DC, while a DC-DC converter functions to change the DC voltage level to another level. The DC-DC converter

1,2,3 Department of Electrical Engineering, Surabaya State Electronics Polytechnic, Jl. Raya ITS, Sukolilo, Surabaya 6011 (phone: 031-5947280; fax: 031-5946114; e-mail: ${ }^{1}$ rizkyfatur05@gmail.com, 2eka@pens.ac.id, ${ }^{3}$ rachmaevin@pens.ac.id) can be a series of converters such as buck, boost, buck-boost, sepic, flyback, and zeta, which are frequently used in LED driver circuits. Efficient and reliable operations of the converter help LED lamps to be efficient and reliable [3]-[5].

Considering various advantages of LEDs, a series of lighting load systems are assembled through dimming control to regulate the light intensity of LEDs that can be adjusted (dimmable) through the LED dimming controller. For instance, it can adjust the light intensity when the lighting loads needed are $100 \%, 70 \%$, or $50 \%$ out of the total light intensity generated by the lighting loads with current capacities are $0.83 \mathrm{~A}, 0.66 \mathrm{~A}$, and $0.5 \mathrm{~A}$. It definitely can save the use of electrical power since the light intensity can be controlled as needed. As a result, the efficiency of the lighting load use is obtained, so is the absorption of power from the lighting load used.

The system used a load of $100 \mathrm{~W}$, therefore, an electronic circuit in the form of an LED driver using a fuzzy logic controller (FLC) was needed. In addition to that, it served as a controller to obtain dynamic responses. The driver responded to the need for loads and generated the current and voltage parameters in accordance with the parameters needed to turn on the LEDs. The light intensity generated by LEDs could be adjusted according to the setting point which was determined based on the existing standards. Moreover, converter circuits were needed to generate the DC voltage for the LED ignition driver which had been integrated in a closed-loop equipped with dimmable LEDs for the lighting level setting. FLC was used to obtain dynamic current responses when there was a change in the lighting generated by LEDs.

\section{SYSTEM CONFIGURATIONS}

In designing a dimmable high-power LED (HPL) system, which the light intensity was adjustable and FLC was used to maintain a stable current, a system configuration was obtained as in Fig. 1. Fig. 1 presents a closed-loop system using a flyback converter to generate DC voltage as a controller of LED light intensity with a constant current for the LEDs which maximum power is $100 \mathrm{~W}$. The LEDs would light up based on the dimming input which served as the set point change settings that had been inputted. The feedback was a current sensor functioned as variable input parameter reader of the FLC. By employing the FLC method as a controller applied to the integrated LED driver, the duty cycle value could be adjusted so that it could produce light with dimming in accordance with the specified current setting points, which were $0.83 \mathrm{~A}, 0.66 \mathrm{~A}$, and $0.5 \mathrm{~A}$ out of the maximum value of the generated light intensity. It referred to the light intensity characteristic toward the LED specification's current with a specified rating. The setting was conducted with the help of data obtained from the current sensor as reading feedback of the FLC input variable 


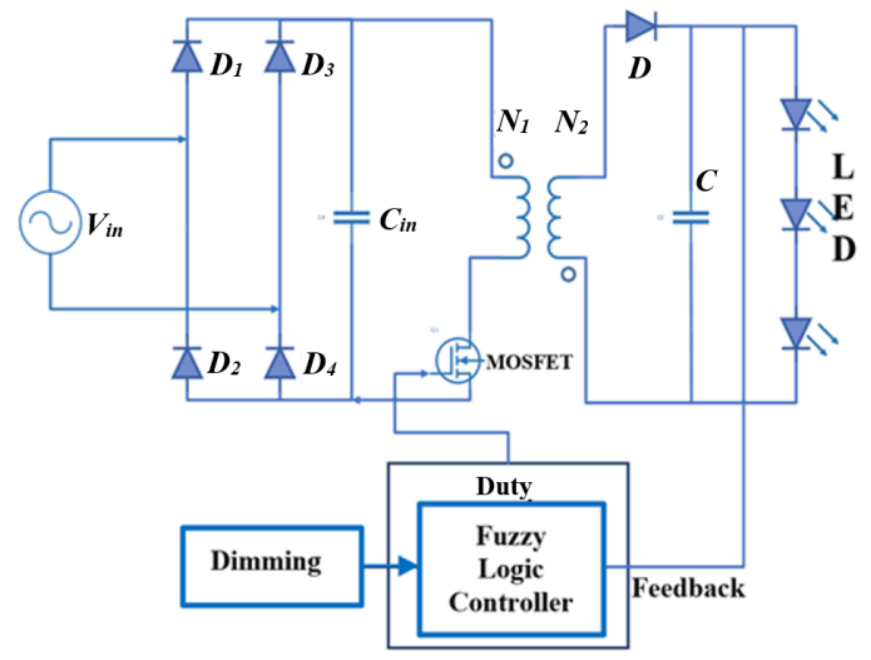

Fig. 1 System diagram.

parameters using the proposed method in order to obtain a power that was in accordance with the needs of the LED lamps, therefore gaining dynamic responses.

\section{A. High Power LED (HPL)}

The power characteristic of HPL is its main parameter which depicts the characteristic of LED PN chip, with its nonlinear behavior, that operates when the applied current and voltage are denoted as an exponential relationship. Fig. 2 is the characteristic curve of HPL voltage depicting the nonlinear relationship curve of the normal operation of voltage drop and current. As shown in Fig. 2, when the forward bias of the LEDs exceeds the threshold, the current will increase as the voltage increases. Minor changes in the voltage will cause significant changes in current [6]. This paper used LED 5730 SMD with a voltage rating of $120 \mathrm{~V}$ and power of $100 \mathrm{~W}$.

Fig. 2 shows the I-V characteristic data of the HPL specification with a rating of $120 \mathrm{~V}, 100 \mathrm{~W}$. Meanwhile, Fig. 3 depicts the LED light intensity that is determined by the current flowing through LEDs. A current that is too high will attenuate the LED light, while a current that is too weak will correspondingly affect the intensity of the LED light. Therefore, a constant-voltage source driver cannot guarantee the LED brightness uniformity and will affect the LED usage period. Only a constant current driver can simultaneously guarantee the reliable use of HPL and the desired level of light intensity [7], [8]. Considering these HPL characteristics, drivers become essential to ensure the stability of the lamp and the reliability of the performance. The power supply driver of the first LED circuit design must meet the following basic requirements.

1) Constant Current Driver: The constant current driver guarantees the stability and reliability of the LED performance, which is also related to the system's efficiency and reliability.

2) High Efficiency: The driver circuit is a special circuit designed for LED light power supply. The driver circuit needs to be simple and compact so it is not space-consuming. Furthermore, it needs to have a high conversion efficiency. A

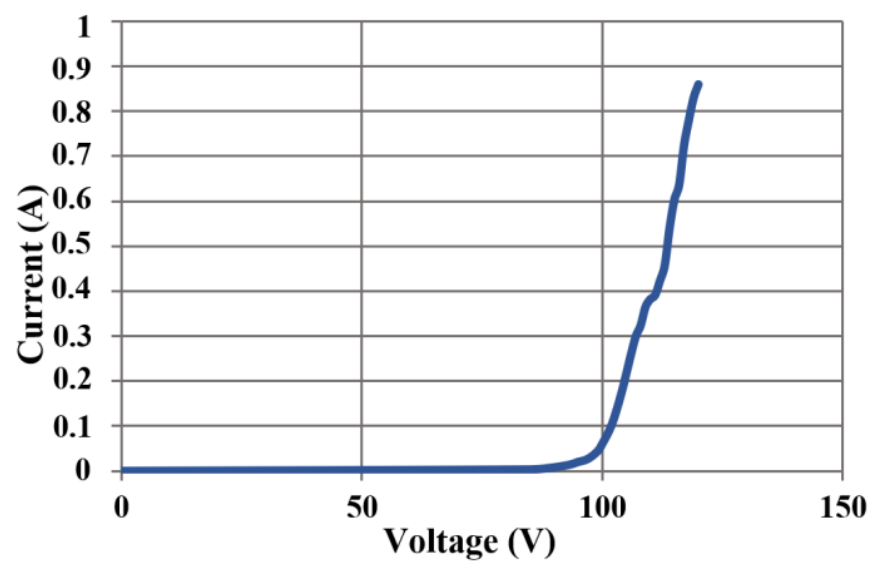

Fig. 2 Current-voltage characteristics of the 120 V 100 W LED.

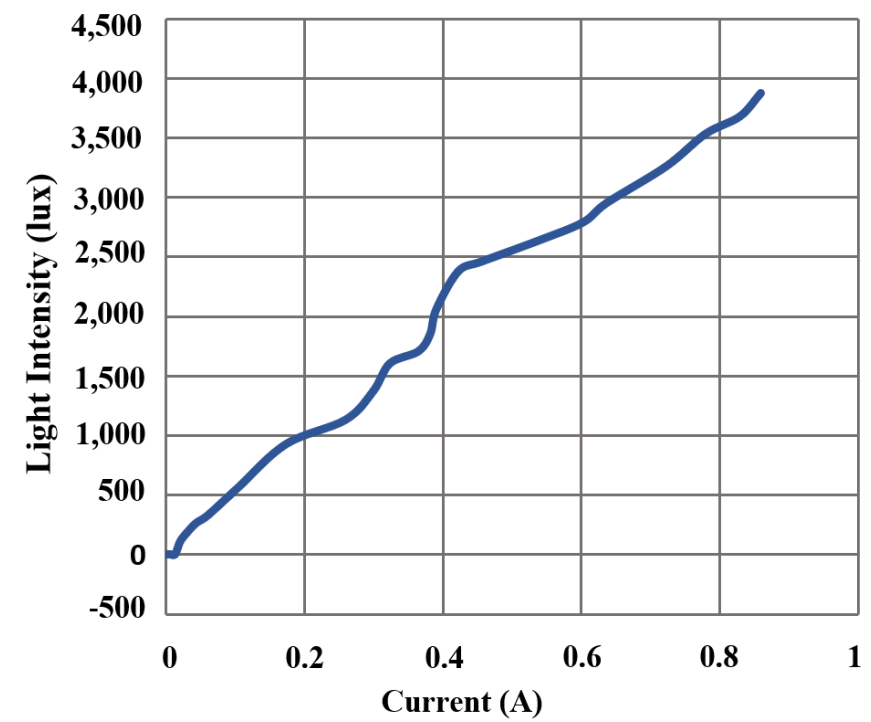

Fig. 3 Lux-current characteristics of the 120 V 100 W LED.

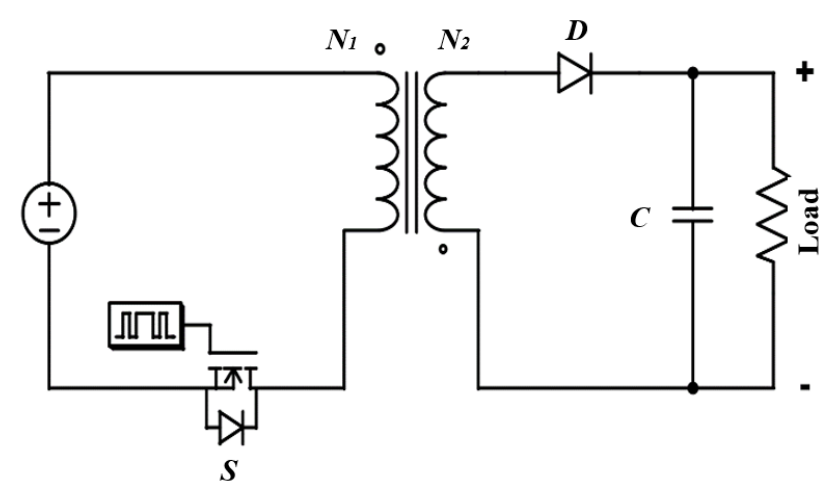

Fig. 4 Flyback converter circuit.

more efficient driver circuit reduces the power consumption, heat, LEDs' temperature, and increases the actual flux at that time.

3) High Reliability: Due to external fluctuations of the grid voltage, electromagnetic interference, and the environment, various waveform from the grid system will interfere the circuit. Voltage spikes will damage the driver circuit and LEDs. Therefore, when the LED driver circuit is designed, several 


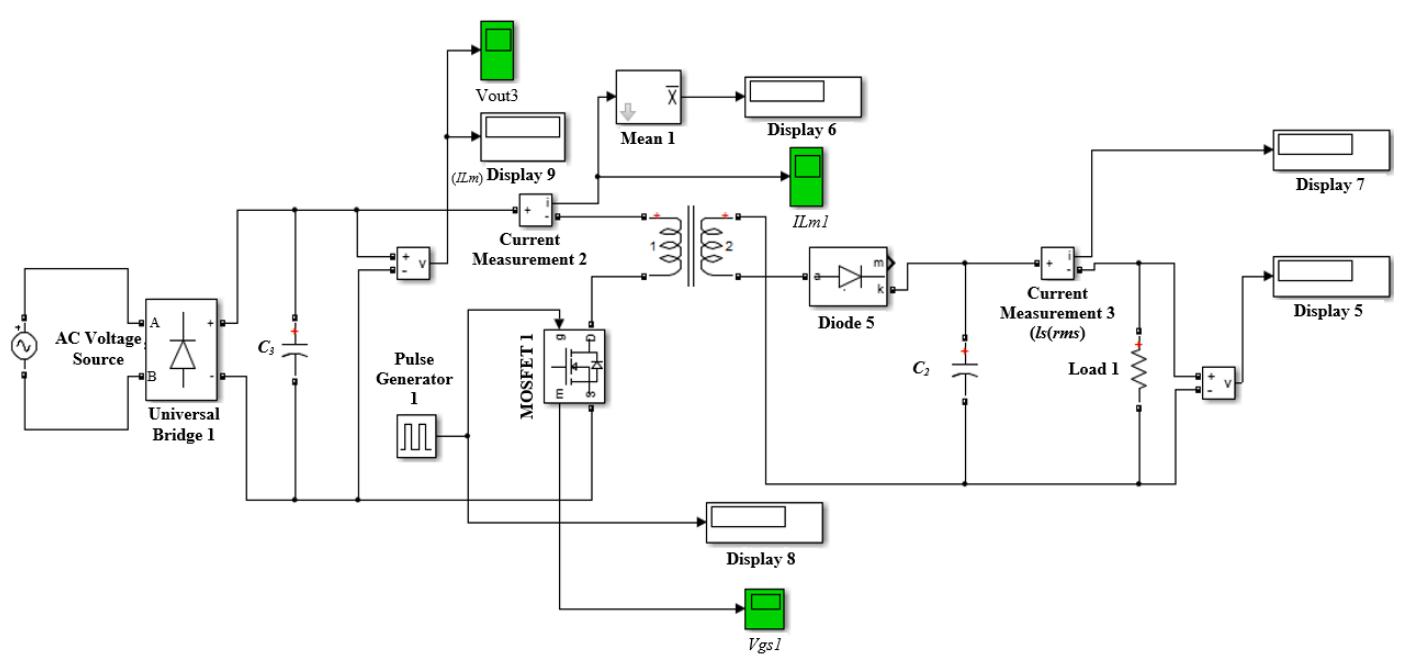

Fig. 5 Full wave rectifier and flyback converter circuit.

measures must be taken to suppress the disturbing spikes. The measures are intended for protecting the driver circuit and LEDs.

\section{B. Flyback Converter}

The flyback topology is designed for the circuit to generate higher or lower output voltage than the input voltage based on the specification that will be used. The flyback converter is a converter that is ascribed to the buck-boost converter topology by replacing the inductor with a transformer. In a transformer, a magnetizing inductor $(\mathrm{Lm})$ and a switch (MOSFET) are connected to the primary ground side. The transformer used is different from an ideal transformer since the current cannot simultaneously flow on the secondary side due to the reverse polarity of the transformer [8], [9]. Since the flyback used a transformer, the load is isolated electrically toward the input. Generally, it is an essential feature of the LED driver, which is frequently required to be electrically isolated [10], [11]. Fig. 4 is the circuit of the flyback converter. Several equations which are used to obtain the parameters of the flyback converter are as follows.

$$
\begin{gathered}
V o=V s \times \frac{D}{1-D}=\frac{N_{2}}{N_{l}} \\
L m=\frac{\left(V d c_{\min } \times D m a k s\right)^{2}}{2 \times \operatorname{Pin} \times F s \times K r f} \\
C=\frac{I o \times D}{F \times \Delta V o}
\end{gathered}
$$

with

$$
\begin{array}{ll}
\text { Vo } & =\text { output voltage }(\mathrm{V}) \\
V s & =\text { input voltage }(\mathrm{V}) \\
\text { Dmaks } & =\text { duty cycle }(\%) \\
\text { Lm } & =\text { transformer inductance }(\mathrm{H}) \\
F s & =\text { frequency switching }(\mathrm{kHz}) \\
\text { Pin } & =\text { input power }(\mathrm{W}) \\
C & =\text { capacitance of a capacitor }(\mathrm{F}) \\
\Delta v o & =\text { voltage ripple }(\mathrm{V}) \\
\text { Krf } & =<1 \mathrm{CCM}[8],[9] .
\end{array}
$$

TABLE I

FLYBACK CONVERTER PARAMETER

\begin{tabular}{|l|l|}
\hline \multicolumn{1}{|c|}{ Parameter } & \multicolumn{1}{c|}{ Value } \\
\hline Vin min & $300 \mathrm{~V}$ \\
\hline Vin max & $310 \mathrm{~V}$ \\
\hline Switching frequency & $40 \mathrm{kHz}$ \\
\hline Iout & $0.83333 \mathrm{~A}$ \\
\hline Vout & $120 \mathrm{~V}$ \\
\hline Np/Ns & $300 / 121.2$ \\
\hline$L$ & $3.164 \mathrm{mH}$ \\
\hline$C$ & $86 \mu \mathrm{F}$ \\
\hline
\end{tabular}

The flyback converter circuit in this system functioned as a controller of the LED driver. The regulated part was the PWM duty cycle so that output voltage was obtained. Parameters that served as component supports were in the flyback converter. These parameters were a high-frequency transformer, MOSFET, capacitor, and diode. The basic circuit of a full-wave rectifier and a flyback converter is shown in Fig. 5.

Table I presents the calculation of the specified design in the form of parameters of input voltage, output voltage, and nominal output current. The system testing was conducted to discover the output response of the converter as parameters to design fuzzy logic controller. This testing was performed by comparing the output current value which was detected by the specified set point. As a result, "error" and "delta error" values were obtained. Fig. 6 presents the voltage output response, while Fig. 7 presents the output current response of the flyback converter.

Fig. 6 shows the overshoot and steady state at a voltage of $120 \mathrm{~V}$. In accordance with the design that had been assembled, the steady-state voltage was $120 \mathrm{~V}$. Fig. 7 shows the overshoot and steady state at a current of $0.833 \mathrm{~A}$. In accordance with the design, the steady-state current was $0.83 \mathrm{~A}$.

\section{Fuzzy Controller}

In this paper, the controller design is aimed to control the current of the flyback converter output so that it fits the specified set point. The fuzzy logic controller would regulate the output of the duty cycle for the flyback converter driver to 


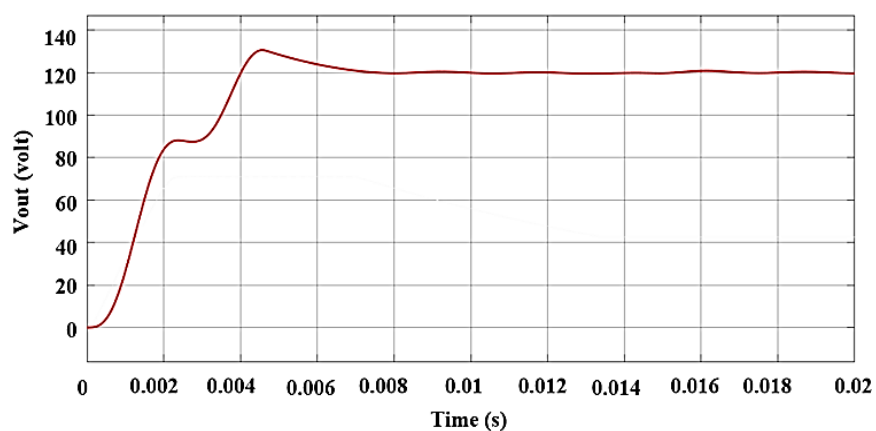

Fig. 6 Voltage output response.

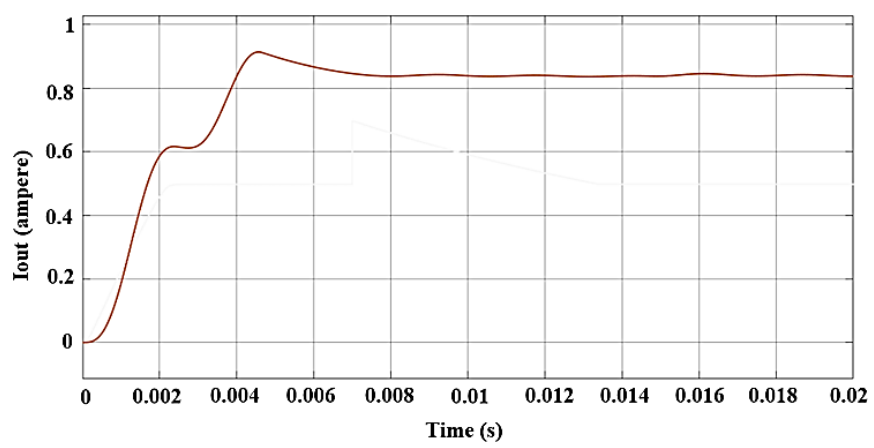

Fig. 7 Output current response.

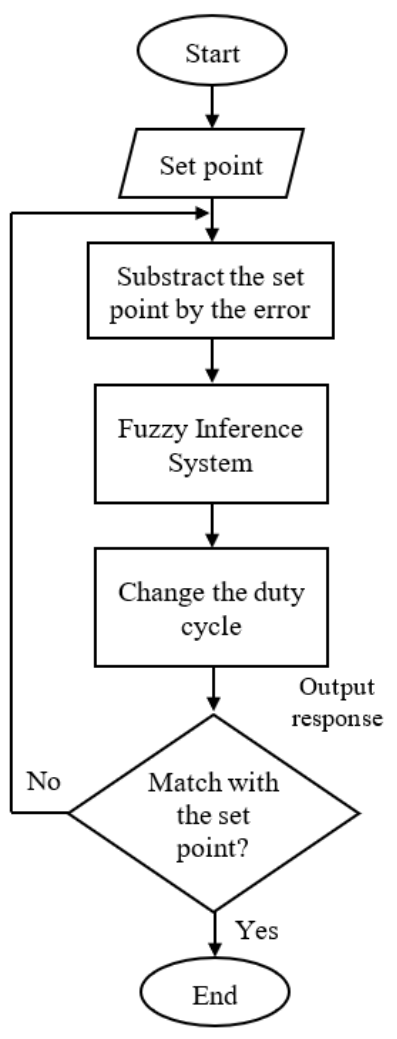

Fig. 8 System flowchart.

generate output voltage for the LED driver. In designing the controller, the mathematical model of the plant did not need to be looked for. A fuzzy-based controller had several steps before it reached the plant, namely fuzzification, base and database

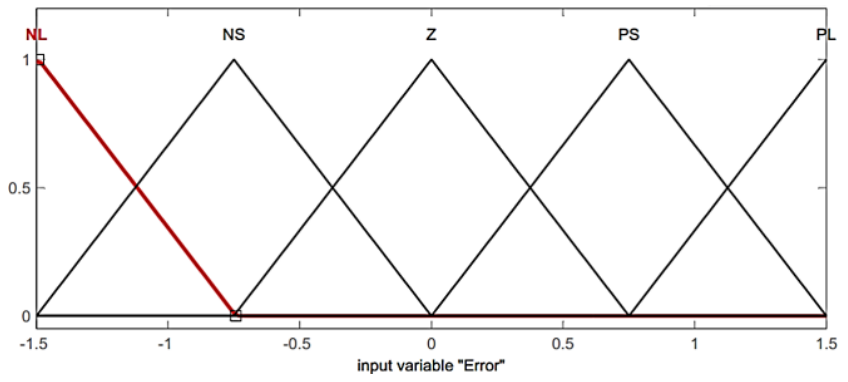

Fig. 9 Design of membership function input "error" of fuzzy logic controller.

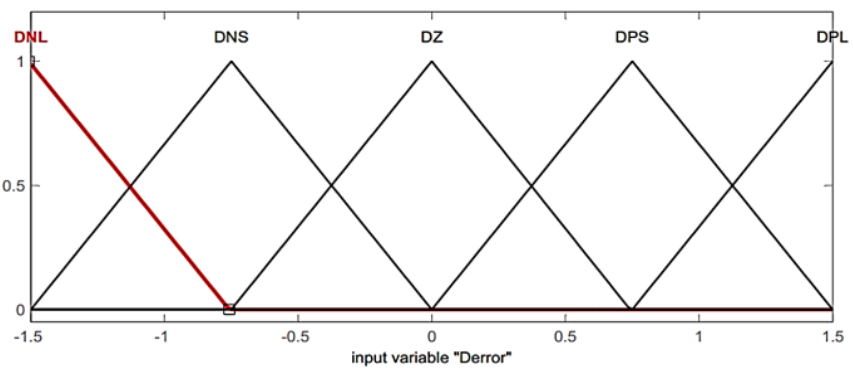

Fig. 10 Design of membership function input "delta error" of fuzzy logic controller.

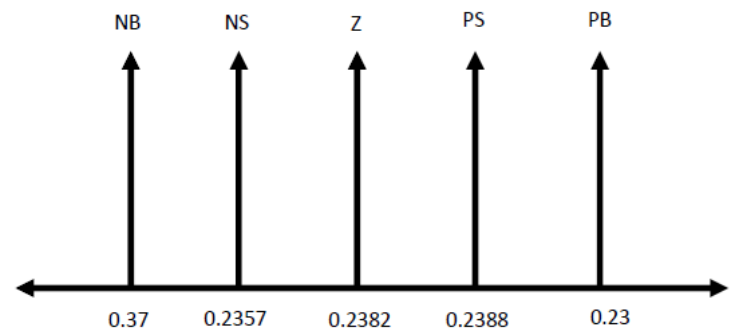

Fig. 11 Design of membership function input "delta error" of fuzzy logic controller.

rule, and defuzzification. The fuzzy logic process is showed as the following [12], [13].

1) Fuzzification: Fuzzification is the process of changing the input of the crisp to the fuzzy (linguistic variables) presented in the fuzzy sets with their respective membership functions.

2) Rule Base: The rule base consists of IF-THEN statements. The rule base fuzzy is determined after the fuzzification process, which consists of fuzzy logic-based rules to denote a condition. The arrangement of this rule base will affect the precision of the model. The decision-making stage is determined based on the rule base design [14], [15]. Table II is the rule base which are used in this paper.

3) Defuzzification: The output for the rule base is fuzzy value, so the defuzzification process is needed to transform the fuzzy value (linguistic variables) to firm values which then is sent to the system or plant. The defuzzification process is conducted by applying the weighted average method. This method calculated the average value using weight in the form of membership degrees so that $x^{*}$ can be calculated using (4).

$$
\mathrm{X}^{*}=\frac{\sum \mu(X) \times X}{\sum \mu(X)}
$$




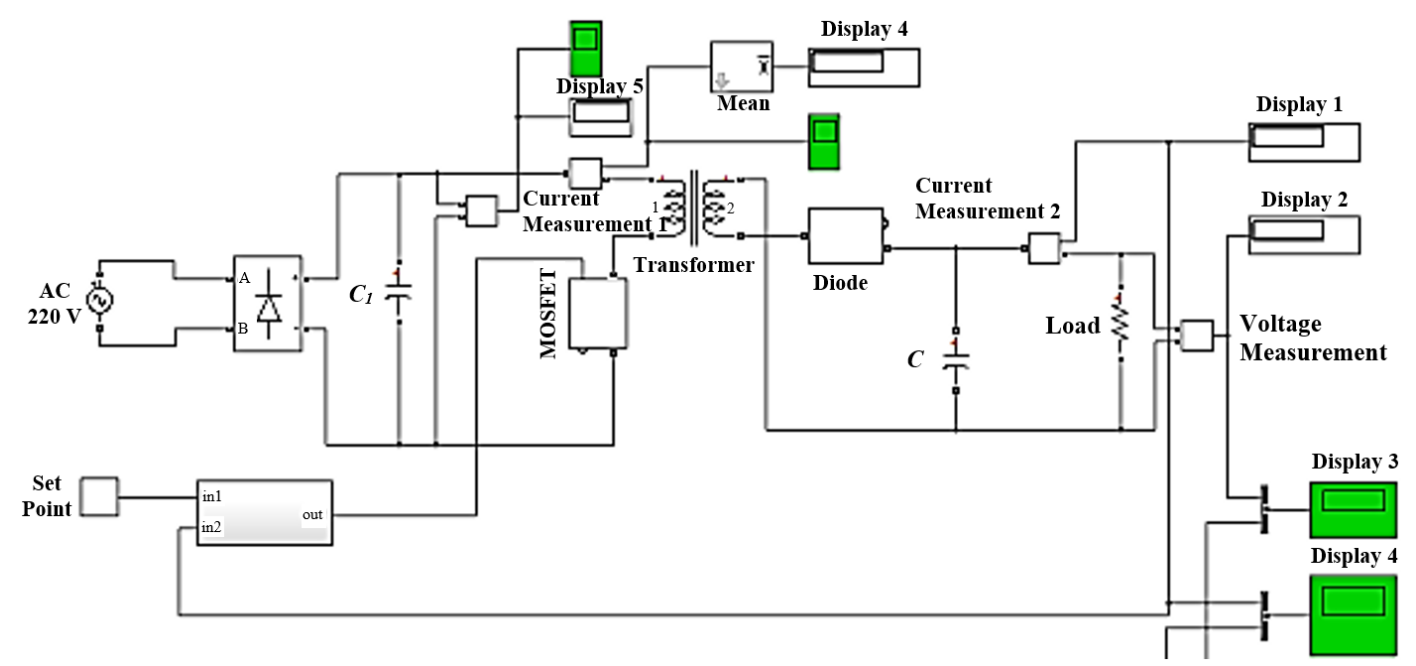

Fig. 12 Closed-loop simulation circuit.

In this paper, fuzzy logic controller would compare the detected output current value with the specified set point, so that the "error" and "delta error" values were obtained. These values were used as an input variable in the fuzzy, while the output variable was a duty cycle. These values would also be used to control the duty cycle on the flyback converter. Fig. 8 shows the system flowchart.

The design of fuzzy controller consists of the fuzzy interface system's design process which are explained as follows.

1) Input Membership Function Design: The first step in processing the fuzzy logic containing domain transformation is called fuzzification. The input crisp is transformed to the fuzzy input. Before changing the form of the crisp input into the fuzzy input, the membership function must first be defined. Then, fuzzification takes real-time input values and compares them with the stored membership information to generate fuzzy input values. Fig. 9 displays fuzzification of input error from crisp to fuzzy (linguistic variables). It is presented in the form of fuzzy sets with membership function values which are obtained from the range determined from the response results. On the other hand, Fig. 10 shows a fuzzification of input delta error from crisp to fuzzy (linguistic variables). It is presented in the form of fuzzy sets which membership function values are obtained from the specified range from the response results minus the previous set point.

2) Output Membership Function Design: In creating the output membership function, values are inputted in the same way as inputting input membership function. In this paper, the singleton membership function, which only had one input, was used. Output membership function in the form of duty cycle had five singleton types representing negative big (NB), negative small (NS), zero (Z), positive small (PS), and positive big (PB) values. It is shown in Fig. 11. Defuzzification techniques used in this paper were the center of gravity (COG). In this method, each output membership function which was higher than the values indicated by each fuzzy output would be truncated. By using the COG fuzzification method, the output values of singleton were combined using the average weight.
TABLE II

RULE BASE IN FUZZY LOGIC CONTROLLER

\begin{tabular}{|c|c|c|c|c|c|}
\hline & NL & NS & $\mathbf{Z}$ & PS & PL \\
\hline NL & PL & PL & PL & NS & Z \\
\hline NS & PL & PL & NS & Z & PS \\
\hline $\mathbf{Z}$ & PL & NS & Z & PS & PL \\
\hline PS & NS & Z & PS & PL & PL \\
\hline PL & Z & PS & PL & PL & PL \\
\hline
\end{tabular}

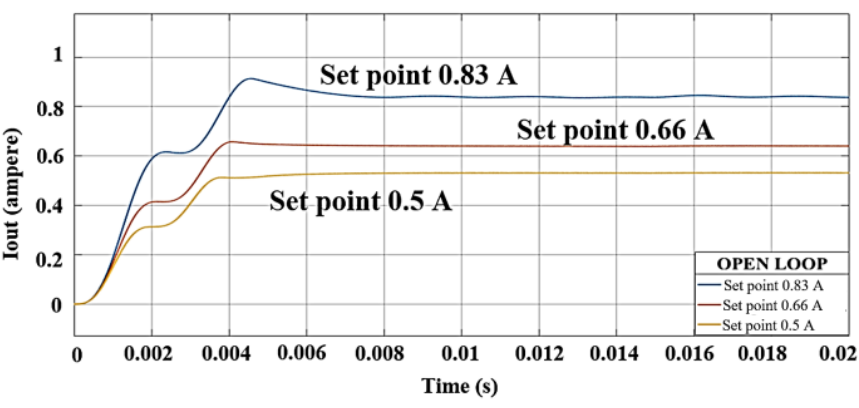

Fig. 13 Open-loop output response of set point variation.

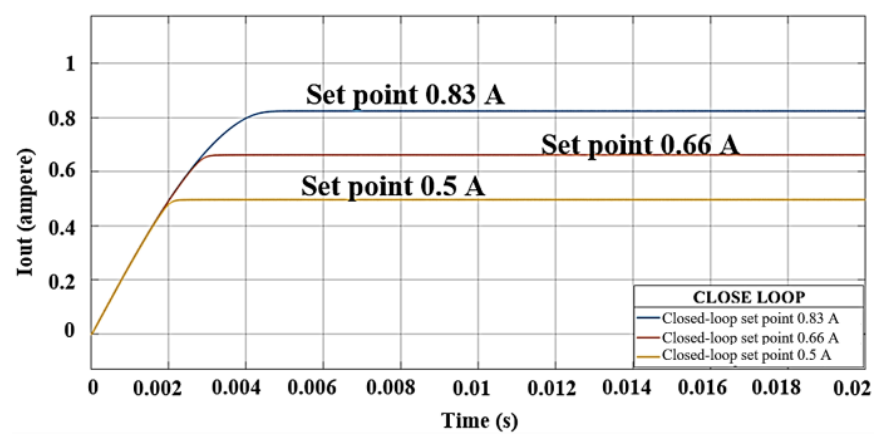

Fig. 14 Closed-loop response output of the set point variation.

The COG formula to calculate singleton reductions is shown in (5).

output $(y)=\frac{\sum_{i}(\text { fuzzy output } i) x(\text { singleton position of } x i \text { axis })}{\sum_{i}(\text { fuzzy output } i)}$

3) Rule Base Design: Table II presents the rules of fuzzy (rule base). These rules usually use IF-THEN statements that 
TABLE III

DATA OF SHIFT PARAMETERS WITH CLOSED-LOOP SYSTEM OF FLYBACK CONVERTER USING FUZZY CONTROL

\begin{tabular}{|c|c|c|c|c|c|c|}
\hline No. & $\begin{array}{c}\text { Set } \\
\text { Point } \\
(\mathbf{A})\end{array}$ & $\begin{array}{c}\text { Rise } \\
\text { Time } \\
(\mathbf{s})\end{array}$ & $\begin{array}{c}\text { Time } \\
\text { Delay } \\
(\mathbf{s})\end{array}$ & $\begin{array}{c}\text { Settling } \\
\text { Time } \\
(\mathbf{s})\end{array}$ & $\begin{array}{c}\text { Steady } \\
\text { State } \\
(\mathbf{A})\end{array}$ & $\begin{array}{c}\text { Error } \\
(\%)\end{array}$ \\
\hline 1 & 0.83 & 0.0041 & 0.00207 & 0.00479 & 0.82 & 0.12 \\
\hline 2 & 0.66 & 0.0025 & 0.00175 & 0.00347 & 0.66 & 0 \\
\hline 3 & 0.50 & 0.0020 & 0.00141 & 0.00313 & 0.49 & 0.8 \\
\hline
\end{tabular}

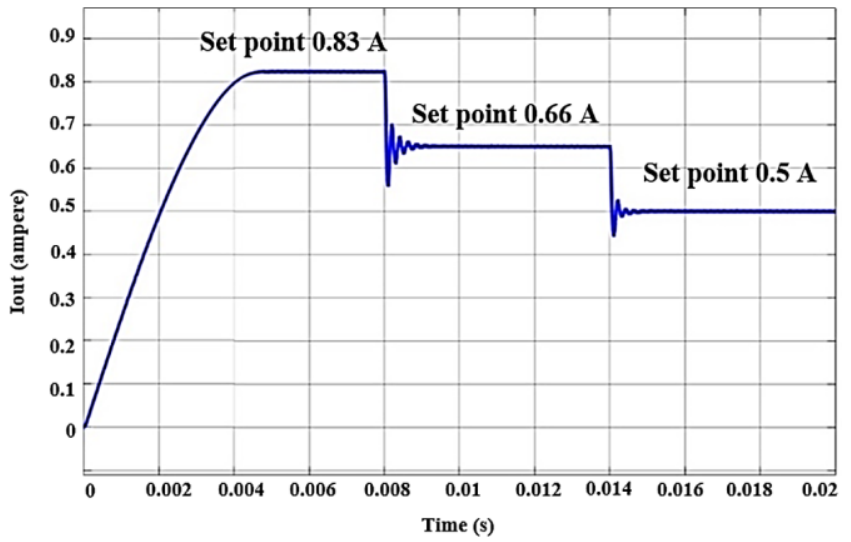

Fig. 15 Set point variation change.

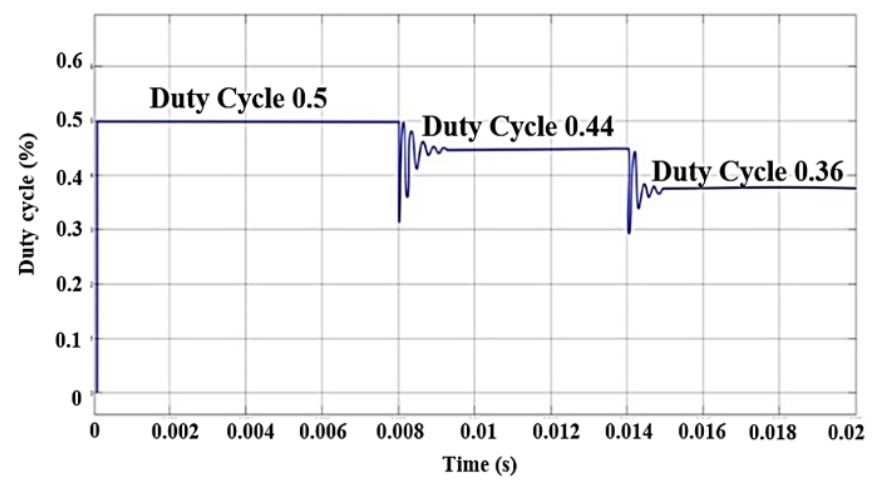

Fig. 16 Closed-loop response output of the set point variation.

depicts the actions which are taken in responding the various fuzzy inputs. These rules follow the behavior of systems and are written in the linguistic table pattern of membership function for two inputs (error and delta error) and output (duty cycle). These rules can be expressed in a matrix as in Table II. Twenty-five rules could be generated from five membership functions of input error and delta error that could determine the value of the singleton output response to be taken.

\section{SIMULATION RESULT AND ANALYSIS}

In this paper, the simulation was carried out using FLC to control the current in the HPL with the aim of gaining good dynamic responses to prevent overcurrent in the LEDs. The testing using this simulation used three set points of $0.83 \mathrm{~A}$, $0.66 \mathrm{~A}$, and $0.5 \mathrm{~A}$. Fig. 12 is a closed-loop circuit figure that aims to determine the output response converter. The first simulation test, using three set points $(0.83 \mathrm{~A}, 0.66 \mathrm{~A}, 0.5 \mathrm{~A})$, was carried out to determine the response without using an open-loop control.

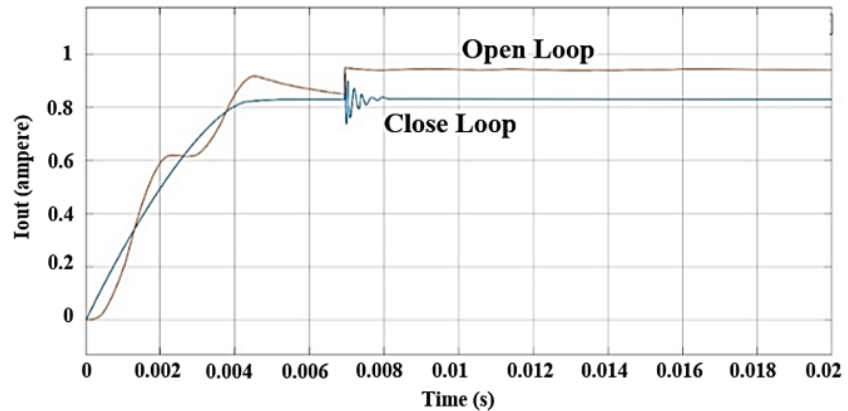

Fig. 17 Output response of closed-loop set point 0.833 A with a given disturbance.

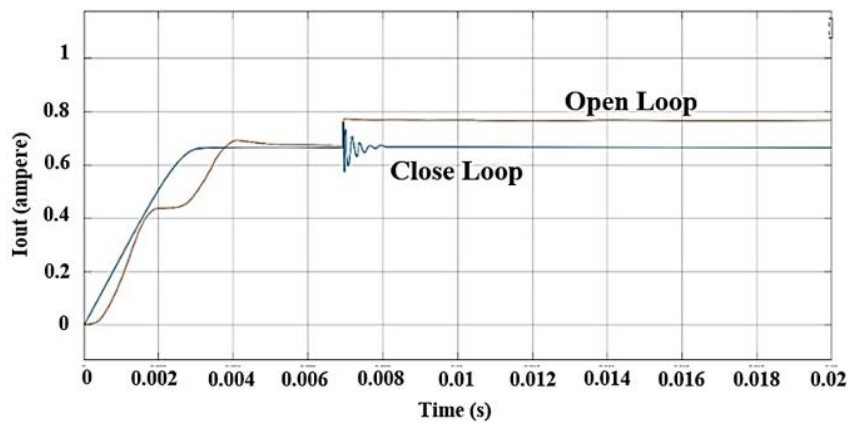

Fig. 18 Output response of closed-loop set point $0.66 \mathrm{~A}$ with a given disturbance.

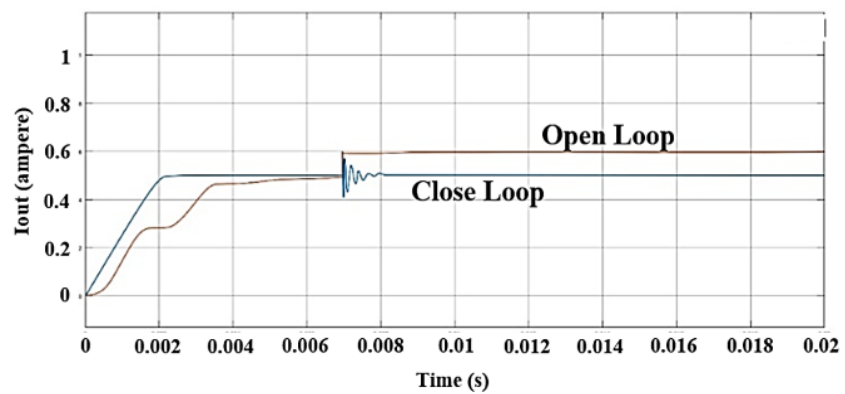

Fig. 19 Response of closed-loop set point $0.66 \mathrm{~A}$ with a given disturbance.

Fig. 13 shows the occurrence of an overshoot in each set point. In the set point of $0.83 \mathrm{~A}$, the steady state occurs at $0.0008 \mathrm{~s}$, while the steady state in the $0.66 \mathrm{~A}$ and $0.5 \mathrm{~A}$ occur at $0.005 \mathrm{~s}$. In this open-loop simulation, the highest set point takes a longer steady state time, which is $0.008 \mathrm{~s}$.

An integrated closed-loop by applying fuzzy logic controller was the second simulation testing. Fig. 14 is the result of the output response using fuzzy logic controller from three specified set points. It shows closed-loop response output. During the closed-loop simulation, the overshoot did not occur; moreover, the steady state response was faster. Table III presents data of closed-loop shift parameters. Shift parameters were the data taken from the shift in each response of the three set points.

The set point was changed in the third simulation testing to determine the control responses when the set point changed from $0.833 \mathrm{~A}, 0.66 \mathrm{~A}$, and $0.5 \mathrm{~A}$. Fig. 15 shows the result of the testing to find out the control system performance. The testing was conducted by changing three set points, namely 
$0.83 \mathrm{~A}, 0.66 \mathrm{~A}$, and $0.5 \mathrm{~A}$. In the testing result graph, the set point changes are made at one time from 0 to $0.02 \mathrm{~s}$. The $0 \mathrm{~s}$ to $0.008 \mathrm{~s}$ is the set point of $0.833 \mathrm{~A}$ with the steady state at 0.82 $\mathrm{A}$, followed by the shift at the set point of $0.66 \mathrm{~A}$. When the shift occurs, the oscillations also occur; meanwhile, the steady state is at $0.66 \mathrm{~A}$. Following the previous shift is the shift at the set point of $0.5 \mathrm{~A}$. When the shift occurs, the oscillations also occur; meanwhile, the steady state is at $0.49 \mathrm{~A}$.

Fig. 16 is the output of the fuzzy control to the MOSFET. In the graph, there are three set point changes. The first set point is $0.83 \mathrm{~A}$ and occurs at $0.001 \mathrm{~s}$ to $0.008 \mathrm{~s}$. Its duty cycle value is 0.5 . The second set point is $0.66 \mathrm{~A}$ and it occurs at 0.008 to $0.014 \mathrm{~s}$. During the set point shift, oscillations occur and the steady state takes place at a duty cycle of 0.44 . The third set point is $0.5 \mathrm{~A}$ and occurs at 0.014 to $0.02 \mathrm{~s}$. During the parameter shift, oscillations occur and the steady state takes place at a duty cycle of 0.36 .

The fourth simulation testing was disturbance test on the output side by giving a step signal at $0.007 \mathrm{~s}$. This control testing aimed to determine the ability of the control to return to the predetermined set point after an overcurrent occurred in the disturbance event. Fig. 17 to Fig. 19 show the result of the simulation with a given disturbance.

The closed-loop testing was compared with an open-loop simulation which was given a disturbance with the step signal on the output side at $0.007 \mathrm{~s}$ was at 0.2 V. Fig. 17 to Fig. 19 show that fuzzy control can return to the predetermined set point. It is shown in the blue graph, i.e., the response can return to the specified set point after a disturbance occurs. On the other hand, the red graph remains on the given disturbance.

\section{CONCLUSION}

A closed-loop simulation testing to the flyback converter using fuzzy logic controller with three set points $(0.83 \mathrm{~A}, 0.66$ $\mathrm{A}$, and $0.5 \mathrm{~A}$ ) has been conducted. It can be deduced that fuzzy logic controller can accelerate the rise time and the system's steady state. Furthermore, fuzzy logic controller is able to return to the specified set point, proving that it can improve the performance when current overshoot occurs in the HPL load and can maintain a constant response at the specified set point.

\section{REFERENCES}

[1] R. Osorio, J.M. Alonso, N. Vázquez, S.E. Pinto, F.D.J. Sorcia-Vázquez, M. Martínez, and L.M. Barrera, "Fuzzy Logic Control with Improved Algorithm for Integrated LED Driver," IEEE Transactions on Industrial Electronics, Vol. 65, No. 9, pp. 6994-7003, Sept. 2018.
[2] E.O. Lindstrom, A. Falcon, M.B. D'Amico, "Modeling and Control of a Flyback Converter to Drive a Dimmable LED Array," 2016 IEEE Biennial Congress of Argentina (ARGENCON), 2016, pp. 1-6.

[3] C.S. Moo, Y.J. Chen, Y.J. Li, and H.C. Yen, “A Dimmable LED Driver with Partial Power Regulation," IECON 2015 - 41st Annual Conference of the IEEE Industrial Electronics Society, 2015, pp. 672-677.

[4] X. Chen, J. Tao, Y. Zhu, and X. Liu, "Optimized Fuzzy Control for LED Constant Current Driver Design," 2010 Seventh International Conference on Fuzzy Systems and Knowledge Discovery, 2010, pp. 1124-1127.

[5] R.L. Lin, J.Y. Tsai, S.Y. Liu, and H.W. Chiang, "Optimal Design of LED Array Combinations for CCM Single-Loop Control LED Drivers," IEEE Journal of Emerging and Selected Topics in Power Electronics, Vol. 3, No. 3, pp. 609-616, Sep. 2015.

[6] M. Walidain, I.D. Sara, and M. Syukri, "Perancangan Sistem Penerangan LED sebagai Sumber Cahaya pada Pengujian Modull Surya," Jurnal komputer, Informasi Teknologi dan Elektro, Vol. 3, No. 2, pp. 46-52, 2018.

[7] H. Wang, Z. Liu, and J. Dong, ”High-Power LED Constant-Current Driver Circuit Design and Effciency Analysis," Proceedings of 2011 Cross Strait Quad-Regional Radio Science and Wireless Technology Conference, 2011, pp. 705-710.

[8] Y. Sawitra, P. Nugroho, E. Firmansyah, W. Dewanto, R. Hartanto, Tiyono, and Tumiran, "Design of a Low-cost High Efficiency Multi Output Self Oscillating Flyback Converter," International Journal of Information Technology and Electrical Engineering, Vol. 1, No. 2, pp. 63-69, Jun. 2017.

[9] K.M. Habsari, Wijono, and D.J. Djoko H.S., "Metode Flyback pada Pembangkitan Tegangan Tinggi untuk Aplikasi Plasma Electrolytic Oxidation," Jurnal Nasional Teknik Elektro dan Teknologi Informasi, Vol. 6, No. 3, pp. 374-379, Aug. 2017.

[10] H. Broeck, G. Sauerlander, and M. Vendt, "Power Driver Topologies and Control Schemes for LED," APEC 07 - Twenty-Second Annual IEEE Applied Power Electronics Conference and Exposition, 2007, pp. 13191325.

[11] M.W. Alim, N.A. Windarko, and R. Rakhmawati, "Fuzzy Logic Control Design on Buck Converter for Thermo Electric Air Cooler Power Supply," Journal on Advanced Research in Electrical Engineering, Vol. 4, No.2, pp. 111-116, 2020.

[12] A.M. Komsari, A. Saberkari, and R. Shahnazi, "Design of a fuzzy PI Controller for Peak-to-average Reduction in Output Current of LED Drivers," 2018 9th Annual Power Electronics, Drives Systems and Technologies Conference (PEDSTC), May 2020, pp. 116-121.

[13] M.P.P. Mary and V. Sivachidambaranathan, "Fuzzy Logic Controller based Multi-port LED Driving," 2017 International Conference on Computation of Power, Energy Information and Commuincation (ICCPEIC), Feb. 2018, pp. 632-638.

[14] A. Setiawan and B. Yanto, Logika Fuzzy dengan MATLAB, 1st ed., Denpasar, Indonesia: Jayaapangus Press, 2018.

[15] O. Setyawati, H. Suyono, H. Mukti Himawan, N. Sulistiyanto, and M. Rif'an, "Prototype of Buck Converter Using Fuzzy Logic Control for LED Driver," 2018 5th International Conference on Electrical and Electronic Engineering (ICEEE), Jun. 2018, pp. 27-30. 